\begin{tabular}{l}
\hline $\mathrm{F}$ \\
1437 \\
$\mathrm{~A} 46$ \\
1913 \\
$\mathrm{SOA}$ \\
\end{tabular}







\section{DOCUMENTOS ANTIGUOS}

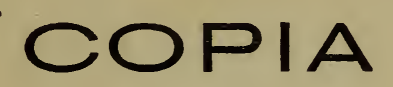

DE DOS CARTAS MANUSCRTTAS DE DON PEDRO.DE ALVARADO DIRIGIDAS $\AA$

\section{HERNANDO CORTES}

11 de Abril y 28 de Julio $\because$

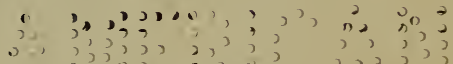

EDITADAIS,

por a. w. Kurtz.

\section{5}

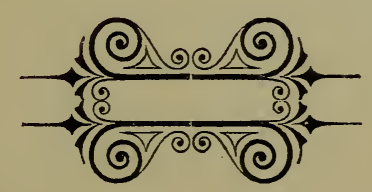

GUATEMALA, C. A.-Tip. Arenales hijos,-1913. 
$=1437$

A 5

$40 \mathrm{and}$ a 


\section{DOS PALABRIS}

Estos dos documentos de la historia de Guatemala que no conocieron Remesal, Fuentes, Ximenez, Vasquez, Juarros ni otros escritores seguramente, y cuya falta nota el Señor Arzobispo García Pelaez, fueron dados á luz en México por González Barcia, en su obra titulada: "Historiadores Primitivos de las Indias Occidentales", impresa en tres volúmenes el año de 1749 de la cual apenas se conoce hoy uno que otro ejemplar.

Barcia no dice de donde las obtuvo; pero Don Paresal de Gallangos en la instrucción que escribió para la edición de las Cartas de Cortés al Emperador Carlos V., folios 7 y 8, dice que los originales se hallan en un Códice, folio menor, que con 640 fojas y bajo el número 120, se encuentra en la Biblioteca Imperial de Viena; el mismo en que se descubrió la primera carta de Cortés al Emperador Carlos V, que tambien se daba por perdida.

La edición de Barcia es muy incorrecta: los nombres de lugares los desnaturaliza completamente; como una prueba de ello, el nombre de Utatlan, Capital del Kiché, aparece en estas Cartas indistintamente convertido en Visatan, Ucatlan, Otutlan, Otubla, etc. Sin embargo, estas Cartas arrojan luz sobre la Historia de América: desvanecen muchas falsas relaciones, cuentos imaginarios, conjeturas novelescas de los cronistas, estados sobre las marchas de Alvarado, fundación de Guatemala $\mathbf{y}$ otros puntos capitales.

Sobre Alvarado, lo que no deja lugar á duda es: del corazón magnánimo é instintos compasivos y cristianos del Señor Don Pedro de Alvarado que gastó con los infelices indios hasta el extremo inaudito de mandarlos herrar como bestias. 



\section{RELACION}

hecha por Pedro de Alvarado á Hernando Cortes, en que se refieren las Guerras y Batallas, para pacificar las provincias de Chapotulan, Chacialtenango y Utlatan, la quema de su Cacique y nombramiento de sus hijos para sucederle: y de tres Sierras de Acije, Azufre y Alumbre.

Stẽ̃or: de Soconusco escribí á Vuestra Merced todo lo que hasta allí me había sucedido, y aun algo de lo que se esperaba haber adelante; y despues de haber enviado mis mensajeros á esta tierra, haciéndoles saber como yo venía á ella á conquistar y pacificar las provincias, que so el dominio de su Magestad no se quisiesen meter, y á ellos como á sus vasallos, pues por tales se habían ofrecido á Vuestra Merced, les pedía favor y ayuda por su tierra, que haciéndolo así, que harían como buenos y leales vasallos de su Magestad; y que de iní y de los españoles de mi compañía serían muy favorecidos y mantenidos en toda justicia; y donde no, que protestaba de hacerles la guerra, como á traidores rebelados y alzados contra el servicio del Emperador nuestro Señor; y que por tales los daba y demas de esto daba por esclavos á todos los que á vida se tomaseñ en la guerra; y despues de hecho todo esto, y despachado los Mensajeros de sus naturales y propios, yo hice alarde de toda mi gente de pié y de caballo; y otro día Sábado de mañana me partí en demanda de su tierra y anduve tres días por un monte despoblado: y estando asentado real la gente de velas que yo tenía puestas, tomaron tres espías de un pueblo de su tierra, llamado Zapotulan; á los cuales pregunté qué á que venían? y me dijeron que á cojer 
miel, aunque notorio fué que eran espías, segun adelante pareció; $\mathrm{y}$ no obstante todo esto yo no los quise apremiar antes los halagué y les dí otro mandamiento y requerimiento como el de arriba y los envié á los Señores del dicho pueblo, y nunca á ello ni á nada me quisieron responder; y despues de llegado á este pueblo, hallé todos los caminos abiertos y muy anchos así el real, como los que atravesaban y los caminos que iban á las calles principales tapados y luego juzgué su mal propósito y que aquello estaba hecho para pelear, y allí salieron algunos de ellos á mí enviados y me decían desde lejos que me entrase en el pueblo á aposentar, para mas á su placer darnos la guerra, como la tenían ordenada, y aquel día asenté real junto allí al pueblo hasta calar la tierra, á ver el pensamiento que tenían: y luego aquella tarde no pudieron encubrir su mal propósito y me mataron é hirieron gente, de los indios de mi compañía; y como me vino el mandado yo envié gente de á caballo á correr el campo, y dieron en mucha gente de guerra la cual peleó con ellos, y aquella tarde hirieron ciertos caballos. E otro día fuí á ver el camino por donde había de ir, y ví como digo, tambien gente de guerra; y la tierra era tan montosa de cacaguatales y arboleda que era mas fuerte para ellos, que no para nosotros, y yo me retraje al Real; y otro día siguiente me partí con toda la gente á entrar en el pueblo y en el camino estaba un rio de mal paso, y teníanlo los indios tomado, y allí peleando con ellos se lo ganamos: y sobre una barranca del rio, en un llano esperé la rezaga, porque era peligroso el paso y traía mucho peligro, aunque no traía todo el mejor recado que podia. $Y$ estando como digo, en la barranca, vinieron por muchas partes por los montes y me torna- 
ron á acometer, y allí los resistimos hasta tanto, que pasó todo el fardaje: y despues de entrados en las casas dimos en las gentes, y siguióse el alcance hasta pasar el mercado, y media legua adelante, y despues volvimos á asentar Real en el Mercado, y aquí estuve dos días corriendo la tierra, y á cabo de ellos me partí para otro pueblo, llamado Quezaltenango, y aqueste dia pasé dos rios muy malos, de Peña tajada, y allí hicimos paso con mucho trabajo, y comenzé á subir un Puerto que tiene seis leguas de largo y en la mitad del camino asenté Real aquella noche; y el puerto era tan agro que apenas podíamos subir los caballos: é otro día de mañana seguí mi camino y encima de un Rebenton hallé una muger sacrificada y un perro, y segun supe de la lengua, era un desafío; é iendonos adelante allé en un paso muy estrecho una albarrada de palizada fuerte, y en ella no había gente ninguna, y acabado de subir el puerto llevaba todos los ballesteros y peones delante de mí, porque los caballos no se podían mandar, por ser fragoso el camino, salieron obra de tres ó cuatro mil hombres de guerra sobre una barranca, y dieron en la gente de los amigos y retrajéronla abajo, y luego los ganamos: $y$ estando arriba recojiendo la gente para rehacerme, ví mas de treinta mil hombres que venían á nosotros y plugó á Dios que allí hallamos unos llanos y aunque los caballos iban cansados y fatigados del puerto, los esperamos hasta tanto que llegaron á echarnos flechas y rompimos en ellos, y como nunca habían visto caballos cobraron mucho temor, y hicimos un alcance muy bueno y los derramamos y murieron muchos de ellos y allí esperé toda la gente y nos recojimos y fuimos á apasentar una legua de allí á unas fuentes de agua, 
porque allí no la teníamos y la sed nos aquejaba mucho, que segun ibamos cansados, donde quiera tomáramos por buen asiento, y como eran llanos yo tomé la delantera con treinta de caballo; y muchos de nosotros llevábamos caballos de refrezco, y toda la gente demas venía hecha un cuerpo, y luego bajé á tomar el agua. Estando apeados bebiendo, vimos venir mucha gente de guerra á nosotros, y dejámosla llegar, que venían por unos llanos muy grandes y rompimos con ellos, y aquí hicimos otro alcance muy grande donde hallamos gente, que esperaba uno de ellos á dos de caballo, y seguimos el alcance bien una legua, y llegabánsenos ya á una sierra y allí hicieron rostro y yo me puse en huida con ciertos de caballo, por sacarlos al campo, y salieron con nosotros hasta llegar á las colas de los caballos, y despues que me rehice con los de caballo, do vuelta sobre ellos, y aquí se hizo un alcance y castigo muy grande, en esta murió uno de los cuatro Señores de esta Ciudad de Vilatan, que venía por Capitan General de toda la tierra y yo me retraje á las fuentes y allí asenté Real aquella noche, harto fatigados y españoles heridos y caballos; y otro día de mañana me partí para el pueblo de Quezaltenango, que estaba una legua, y con el castigo de antes le hallé despoblado y no persona ninguna en él, y allí me aposenté y estuve reformándome y corriendo la tierra, que es tan grande poblacion como Tascalteque y en las labranzas ni mas ni menos y friisima en demasia, y al cabo de tres días que había que estaba allí, un jueves á medio día asomó mucha multitud de gente en muchos cabos, que segun supe de ellos mismos, eran de dentro de esta Ciudad doce mil y de los pueblos comarcanos y de los demás dicen que no se pudo con- 
tar; y desque los ví puse la gente en órden y yo salí á darles la batalla en la mitad de un llano que tenía tres leguas de largo, con noventa de caballo, y dejé gente en el Real que le guardase que podría ser un tiro de ballesta de Real no mas, y allí comenzamos á romper por ellos y los desvaratamos por muchas partes, y les seguí al alcance dos leguas y media, hasta tanto que toda la gente había rompido, que no llevaba ya nada por delante y despues volvimos sobre ellos y nuestros amigos y los peones hacían una destruccion, la mayor del mundo, en un arroyo y cercaron una sierra rara donde se acogieron, y subiéronles arriba y tomaron todos los que allí se habían subido. Aqueste dia se mató y prendió mucha gente, muchos de los cuales eran capitanes y Señores y personas señaladas, é desque los Señores de esta Ciudad supieron que su gente era desvaratada acordaron ellos y toda la tierra y convocaron muchas otras provincias para ello y á sus enemigos dieron parias, y los atrajeron para que todos se juntasen y nos matasen, y concertaron de enviarnos á decir que querían ser buenos, y que de nuevo daban la obediencia al emperador nuestro Señor, y que me viniese dentro á esta Ciudad de Vilatan, como despues me trajeron y pensaron que me aposentaría dentro y que despues de aposentados una noche darían fuego á la Ciudad y que allí nos quemarían á todos, sin podérselo resistir, como de hecho llegaron á en efecto su mal propósito, sino que Dios Nuestro Señor no consiente que estos infieles hayan victoria contra nosotros, porque la ciudad es muy fuerte en demasía, y no tiene sino dos entradas; la una de treinta y tantos escalones de piedra muy alta: y por la otra parte una calzada, hecha á mano, y mucha parte de ella ya cortada, para 
aquella noche acabarla de cortar, porque ningun caballo pudiera salir á la tierra; y como la Ciudad es muy junta y las calles muy angostas, en ninguna manera nos pudiéramos sufrir sin ahogarnos, ó por huir del fuego despeñarnos. Y como subimos, que yo me ví dentro y la fortaleza tan grande, y que dentro de ella no nos podríamos aprovechar de los caballos, por ser las calles tan angostas y encaladas, determiné luego de salirme de ella á lo llano; aunque para ello los Señores de la Ciudad me lo contradecian; y me decian que me asentase á comer y que luego me iría por tener lugar de llegar á efecto su propósito: y como conocí el peligro en que estábamos, envié luego gente delante á tomar la calzada y puente para tomar la tierra llana; y estaba ya la calzada en tales términos que apenas podía subir un caballo; y al rededor de la Ciudad habia mucha gente de guerra; y como me vieron pasado á lo llano se arredraron, no tanto que yo no recibí mucho daño de ellos, y yo lo disimulaba todo, por prender á los Señores que ya andaban ausentados; y por mañas que tuve con ellos y con dádivas que les dí para mas asegurarme, yo los prendí y presos los tenia en mi posada, y no por eso los suyos dejaban de me dar guerra por los alrededores, y me herían y mataban muchos de los indios que iban por yerba; y un español cojiendo yerba á un tiro de ballesta del Reàl, de encima de una barranca le echaron una galga y lo mataron: y es la tierra tan fuerte de quebradas, que hay quebradas que entra doscientos estados de hondo, y por estas quebradas no pudimos hacerles la guerra ni castigarlos como ellos merecían: y viendo que con correrles la tierra y quemársela yo los podria traer al servicio de Su Magestad determiné de queınar á 
los Señores; los cuales dijeron al tiempo que los quería quemar, como parecerá por sus confesiones, que ellos eran los que me habian mandado hacer la guerra, y los que la hacian, y de la manera que debian de tener para me quemar en la Ciudad, y con ese pensamiento me habían traido á ella: y que ellos habian mandado á sus vasallos que no viniesen á dar la obediencia al Emperador Nuestro Señor, ni sirviesen ni hiciesen otra buena obra. Y como conocí de ellos tener tan mala voluntad al servicio de su Magestad; y para el bien, sosiego de esta tierra, yo los quemé y mandé quemar la Ciudad y poner por los cimientos; porque es tan peligrosa y tan fuerte, que mas parece casa de ladrones que no de pobladores: y para buscarlos, envié á la Ciudad de Guatemala, que está diez leguas de esta, á decirle y requerirles de parte de su Magestad, que me enviasen gente de guerra así para saber de ellos la voluntad que tenian, como para atemorizar la tierra: y ella fué buena y dijo que la placia, y para esto me envió cuatro mil hombres: con los cuales y con los demás que yo tenia, hice una entrada y los corrí y eché de toda su tierra. Y viendo el daño que se les hacia me enviaron sus mensajeros, haciéndome saber como ya querian ser buenos; y si habían errado que había sido por mandado de sus señores; y que siendo ellos vivos, no osaban hacer otra cosa; y que pues ya ellos eran muertos, que me rogaban que los perdonase; y yo les aseguré las vidas y les mandé que se viniesen á sus casas y poblasen la tierra como antes; los cuales lo han hecho así, y los tengo al presente en el estado que antes solian estar en servicio de su Magestad: y para mas asegurar la tierra, solté dos hijos de los Señores, á los cuales puse en la posesion de sus padres, y creo harán bien todo lo que 
convenga al servicio de su Magestad y al bien de esta tierra. Y cuanto toca á esto de la guerra, no hay mas que decir al presente, sino que todos los que en la guerra se tomaron, se herraron y se hicieron esclavos, de los cuales se dió el quinto de su Magestad al Tesorero Baltazar de Mendoza; el cual quinto se vendió en Almoneda, para que mas segura esté la renta de su Magestad.

De la tierra hago saber á Vuestra Merced, que es templada y sana y muy poblada de pueblos muy recios: y esta Ciudad es bien obrada y fuerte á maravilla y tiene muy grandes tierras de panes y mucha gente sujeta á ella, la cual con todos los pueblos á ella sujetos y comarcanos dejo so el yugo y en servicio de la corona Real de su Magestad. En esta tierra hay una sierra de Alumbre y otra de Acije y otra de Azufre, el mejor que hasta hoy se ha visto que con un pedazo que me trajeron sin afinar, ni sin otra cosa hice media arroba de pólvora muy buena: y por enviar á Argueta, y no querer esperar, no envio á Vuestra Merced cincuenta cargas de ello; pero su tiempo se tiene para cada y cuando fuere mensajero.

Yo me parto para la Ciudad de Guatemala lunes once de Abril, donde pienso detenerme poco, á causa que un pueblo que está asentado en el agua, que se dice Atitlan, está de guerra, y me ha muerto cuatro mensajeros; y pienso con la ayuda de Nuestro Señor, presto lo atraeremos al servicio de su Magestad; porq. segun estoy informado, tengo mucho que hacer adelante, y á esta causa me daré priesa por invernar cincuenta ó cien leguas adelante de Guatemala, donde me dicen y tengo nueva de los naturales de esta tierra de maravillosos y grandes edificios y grandeza de Ciudades que adelante hay. Tambien me han dicho que cinco 
jornadas adelante de una Ciudad muy grande, que está veinte jornadas de aquí, se acaba esta tierra y afirmase en ello; si así es, certísimo tengo que es el estrecho: plegue á Nuestro Señor me dé victoria contra estos infieles, para que yo los traiga á su servicio ó al de su Magestad. No quisiera hacer en pedazos esta relacion, sino desde el cabo de todo, porque mas tuviera que decir. La gente de Españoles de mi compañía de pié y de caballo, lo han hecho tan bien la guerra que se ha ofrecido, que son dignos de muchas mercedes. Al presente no tengo mas que decir que de sustancia sea, sino que estamos metidos en la mas recia tierra de gente que se ha visto; y para que nuestro Señor nos dé victoria, suplico á Vuestra Merced mande hacer una procesion en esa Ciudad de todos clérigos y frailes para que Nuestra Señora nos ayude; pues estamos tan apartados de socorro, si de allá no nos viene. Tambien tenga Vuestra Merced cuidado de hacer saber á su Magestad como le servimos con nuestras personas, haciendas y á nuestra costa, lo uno para descargo de la conciencia de Vuestra Merced, y lo otro para que su Magestad nos haga mercedes. Nuestro Señor guarde el muy magnífico estado de Vuestra Merced, por largo tiempo, como desea. De esta Ciudad de Uclatan á once de Abril.

Y segun llevo el Viaje largo, pienso me faltará el herraje, si para este verano que viene Vuestra Merced me pudiere proveer de herraje, será gran bien, y su Magestad será muy servido en ello, que agora vale entre nosotros ciento y noventa pesos la docena, y así la mercamos y pagamos ahora.

Beso las Manos de Vuestra Merced.

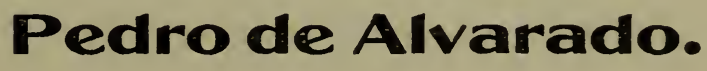




\section{OTRA RELACION}

hecha por Pedro de Alvarado a Hernando Cortes, en que se refiere la conquista de muchas Ciudades, las guerras, batallas, traiciones y rebeliones, que sucedieron y la poblacion que hizo de una Ciudad.-De dos voleanes: uno que exhalaba fuego, y otro humo, de un rio hirviendo y otro frio, y como quedó Alvarado herido de un flechazo.

Ser̃or: de las cosas que hasta Uclatan me habian sucedido, así en la guerra como en lo demas, hice larga relacion á Vuestra Merced; y ahora le quiero hacer relacion de todas las tierras que he andado y conquistado y de todo lo demas que me ha sucedido, y es:

Que yo, Señor, partí de la Ciudad de Uclatan y vine en dos dias á esta Ciudad de Guatemala, donde fuí muy bien recibido de los Señores de ella, que no pudiera ser mas en casa de nuestros padres; y fuimos tan proveídos de todo lo necesario, que ninguna cosa hubo falta: y dende á ocho días que estaba en esta Ciudad, supe de los Señores de ella, como á siete leguas de aquí estaba otra Ciudad sobre una laguna muy grande; y que aquella hacía guerra á esta y á Uclatan y á todas las demas á ella comarcanas por la fuerza del agua y canoas que tenian y que de allí salían á hacer salto de noche en la tierra de estos; y como los de esta Ciudad vieron el daño que de allí recibían me dijeron como ellos eran buenos y que estaban en el servicio de su Magestad y que no querian hacerle guerra ni darla sin mí licencia y rogándome que lo remediase; y yo les respondí que yo los en- 
viaria á llamar de parte del Emperador nuestro Señor; y que si viniesen que yo les mandaria que no les diesen guerra ni le hiciesen mal en su tierra como hasta entonces lo habian hecho, donde no, que yo iria juntamente con ellos á hacerles la guerra y castigarlos. Por manera que luego les envié dos mensajeros naturales de esta Ciudad á los cuales mataron sin temor ninguno. $\mathrm{Y}$ como yo lo supe viendo su mal propósito, me partí de esta Ciudad contra ellos con sesenta de caballo y ciento y cincuenta peones y con los Señores y naturales de esta tierra, y anduve tanto que aquel dia llegué á su tierra y no me salió á recibir gente ninguna de paz ni de otra manera: y como esto ví me metí con treinta de caballo por la tierra á la costa de la laguna, ya que llegamos cerca de un Peñol poblado, que estaba en el agua vimos un escuadron de gente muy cerca de nosotros y yo les acometí con aquellos de caballo que llevaba; y siguiendo el alcance de ellos, se metieron por una calzada angosta, que entraba al dicho Peñol, por donde no podían andar de caballo; y allí me apée con mis compañeros y á pié juntamente y á las vueltas de los indios nos entramos en el Peñol de manera que no tuvieron lugar de romper puentes, que á quitarlas no pudieramos entrar. En este medio tiempo llegó mucha gente de la mia que venía atrás y ganamos el dicho Peñol que estaba muy poblado y toda la gente de él se nos echó á nado á otra isla y se escapó mucha gente de ella, por causa de no llegar tan presto trescientas canoas de amigos que traian por el agua; y yo me salí aquella tarde fuera del Peñol con toda mi gente y asenté real en un llano de maizales, donde dormí aquella noche: y otro dia de mañana nos encomendamos á Nuestro Señor y fuimos por la poblacion 
adelante que estaba muy fuerte á causa de muchas peñas y ceberucos que tenía y hallámosla despoblada, que como perdieron la fuerza que en el agua tenian no osaron esperar en la tierra; aunque todavía esperó alguna poca de gente allá al cabo del pueblo; y por la mucha agrura de la tierra, como digo, no se mató mas gente; y allí asenté real á medio dia y les comenzé á correr la tierra, y tomamos ciertos indios naturales de ella á tres de los cuales yo envié por mensajeros á los Señores de ella, amonestándoles que viniesen á dar la obediencia á sus Magestades y á someterse so su corona imperial y á mí en su nombre: y donde no, que todavía seguiría la guerra y los correria y buscaría por los montes; los cuales me respondieron que hasta entonces, que nunca su tierra habia sido rompida ni gentes por fuerza de armas les habían entrado en ella; y que pues yo había entrado, que ellos holgaban de servir á su Magestad así como yo se los mandaba; y luego vinieron y se pusieron en mi poder y yo les hice saber la grandeza y Poderio del Emperador nuestro Señor; y que mirasen que por lo pasado yo en su real nombre lo perdonaba: y que de allí en adelante fuesen buenos y que no hiciesen guerra á nadie de los comarcanos, pues que eran todos ya vasallos de su Magestad y los envié y dejé seguros y pacíficos y me volví á esta Ciudad: y dende á tres dias que llegué á ella, vinieron todos los Señores y principales y capitanes de la dicha Laguna á mí con presente y me dijeron que ya ellos eran nuestros amigos y se hallaban dichosos de ser Vasallos de su Magestad por quitarse de trabajos y guerras y diferencias que entre ellos había; y yo les hice muy buen recibimiento y les dí de mis joyas y los torné á enviar á su tierra con mucho amor 
y son los mas pacíficos que en esta tierra hay.

Estando en esta Ciudad vinieron muchos Señores de otras provincias de la costa del sur á dar la obediencia á sus Magestades y diciendo que ellos querían ser sus Vasallos y no querían guerra con nadie; y que para esto yo les recibiese por tales y los favoreciese y mantuviese en justicia. $Y$ yo los recibí muy bien, como era razon y les dije que de mí, en nombre de Su Magestad serían muy favorecidos y ayudados y me hicieron saber de una provincia que se dice Yscuintepeque, que estaba algo mas la tierra adentro, como no les dejaba venir á dar la obediencia á su Magestad; y aun no solamente esto, pero que otras provincias que están de aquella parte de ella, estaban con buen propósito y querian venir de paz y que aquesta no les dejaba pasar, diciéndoles que adonde iban y que eran locos, sino que me dejasen á mí ir allá y que todos me darían guerra. Y como yo fuí certificado ser así, así por las dichas provincias, como por los Señores de esta Ciudad de Guatemala me partí con toda mi gente de pié y de caballo y dormí tres días en un despoblado; y otro día de mañana ya que entraba en los términos del dicho pueblo, que es todo arboledas muy espesas, hallé todos los caminos cerrados y muy angostos, que no eran sino sendas porque con nadie tenía contratacion, ni camino abierto y eché los ballesteros delante, porque los de caballo allí no podían pelear por las muchas sienegas y espesura, de monte; y llovia tanto que con la mucha agua, las velas y espías suyas se retrajeron al pueblo; y como no pensaron que aquel día llegara á ellos, descuidaronse algo y no supieron de mi ida, hasta que estaba con ellos en el pueblo; y como entre toda la gente de guerra estaba en los cauces por el amor del agua, me- 
tidos; y cuando se quisieron juntar, no tuvieron lugar, aunque todavía esperaron algunos de ellos y me herieron españoles y muchos de los indios amigos, que llevaba, y con la mucha arboleda y agua que llovía se metieron por los montes que no tuve lugar de les hacer daño ninguno, mas de quemarles el pueblo, y luego les hice mensajeros á los Señores, diciéndoles que viniesen á dar la obediencia á Sus Magestades y á mí en su nombre, sino que les haría mucho daño en la tierra y les talaría sus maizales; los cuales vinieron y se dieron por Vasallos de su Magestad y yo los recibí y mandé que fuesen de allí adelante buenos y estuve ocho días en este pueblo, y aquí vinieron otros muchos pueblos y provincias de paz, los cuales se ofrecieron Vasallos de el Emperador Nuestro Señor.

$\mathrm{Y}$ deseando calar la tierra y saber los secretos de ella, para que su Magestad fuese mas servido y tuviese y señoriase mas tierras, determiné de partir de allí y fuí á un pueblo que se dice Atiepar, donde fuí recibido de los Señores y naturales de él y este es otra lengua y gente por sí; y ápuesta del Sol, sin propósito ninguno remaneció despoblado y alzado y no se halló hombre en todo él. $Y$ porque el riñon del invierno, no me tomase, y me impidiese mi camino, dejelos así, y paseme de largo llevando todo recado en mi gente $\mathrm{y}$ fardaje, porque mi propósito era de calar cien leguas adelante, y de camino ponerme á lo que me viniese hasta calar á ellas y despues dar la vuelta sobre ellos y venir pacificándoles. Y otro día siguiente me partí y fuí á otro pueblo, que se dice Tacuylula, y aquí hicieron lo mismo que los de Atiepar, que me recibieron de paz, y se alzaron dende á una hora. Y de aquí me partí y fuí á otro pueblo que se dice Taxisco, que es muy recio y de mucha 
gente y fuí recibido, como de los otros de atras, y dormí en él aquella noche y otro día me partí para otro pueblo que se dice Nacendelan muy grande; y temiéndome de aquella gente que no la entendía, dejé diez de caballo en la rezaga y otros diez en el medio del fardaje, y seguí mi camino; y podria ir dos ó tres leguas del dicho pueblo de Taxisco cuando supe que había salido gente de guerra y que habían dado en la rezaga en que me mataron muchos indios de los amigos y me tomaron mucha parte del fardaje $y$ todo el hilado de las ballestas y el herraje que para la guerra llevaba que no se les pudo resistir. Y luego envié á Jorje de Alvarado, mi hermano, con cuarenta ó cincuenta de caballo, á buscar aquello que nos habian tomado y halló mucha gente armada en el campo y él peleó con ellos y los desvarató y ninguna cosa de lo perdido se pudo cobrar, porque la ropa que ya la habian hecho pedazos y cada uno traía en la guerra su pampanilla de ella; y llegado á este pueblo de Nacendelan, Jorje de Alvarado se volvió, porque todos los indios se habian alzado á la sierra; y desde aquí torné á enviar á Don Pedro con gente de pié que los fuese á buscar á las sierras, por ver si los pudiéramos traer al servicio de Su Magestad y nunca pudo hacer nada, por la grande espesura de los montes, y así se volvió: y yo les envié mensajeros indios de sus mismos naturales, con requerimientos y mandamientos; $\mathrm{y}$ apercibiéndolos que si nó venian los haria esclavos: y con todo esto no quisieron venir, ni los mensajeros ni ellos. Y al cabo de ocho dias que había que estaba en este pueblo de Nacendelan, vino un pueblo que se dice Pasaco, de Paz que estaba en el camino, por donde habíamos de ir y yo lo recibí y le dí de lo que tenía y les rogué que fuesen bue- 
nos. Y otro dia de mañana me partí para este pueblo y hallé á la entrada de él los caminos cerrados y muchas flechas hincadas; y ya que entraba por el pueblo, ví que ciertos indios estaban haciendo cuartos un perro á manera de sacrificio; y dentro el dicho pueblo dieron una grita $\mathrm{y}$ vimos mucha multitud de gente de tierra $y$ entramos por ellos rompiendo en ellos hasta que los echamos del pueblo, y seguimos el alcance todo lo que se pudo seguir; y de allí me partí á otro pueblo que se dice Mopicalco y fuí recibido ni mas ni menos que de los otros: y cuando llegué al pueblo no hallé persona viva; y de aquí me partí para otro pueblo llamado Acatepeque, á donde no hallé á nadie, antes estaba todo despoblado. Y siguiendo mi propósito que era de calar las dichas cien leguas me partí á otro pueblo, que se dice Acaxual, donde bate la mar del Sur en él; y ya que llegaba á media legua del dicho pueblo, ví los campos llenos de gente de guerra de él, con sus plumajes y divisas y con sus armas ofensivas y defensivas, en mitad de un llano que me estaban esperando, y llegué de ellos hasta un tiro de ballesta y allí me estuve quedo hasta que acabó de llegar mi gente; y desque la tuve junta me fuí obra de media tiro de ballesta hta. la gente de guerra y en ellos no hubo ningun movimiento ni alteracion á lo que yo conocí: y pareciome que estaban algo cerca de un monte donde se me podrían acoger; y mande que se retrajese toda mi gente que éramos ciento de caballo y ciento cincuenta peones y obra de cinco ó seis mil indios amigos nuestros y así nos íbamos retrayendo y yo me quedé en la rezaga haciendo retraer la gente; fué tan grande el placer que hubieron desque me vieron retraer que me vinieron siguiendo hasta llegar á las colas de los caballos, las flechas 
que echaban pasaban en los delanteros; y todo aquesto era en un llano, que para ellos ni para nosotros no había donde estropezar. Ya cuando me ví retraido un cuarto de legua, á donde á cada uno le habian de valer las manos y no el huir, dí vuelta sobre ellos con toda la gente y rompimos por ellos; y fué tan grande el destrozo que en ellos hicimos que en poco tiempo no había ninguno de todos los que salieron vivos; porq. venian tan armados que el que caía en el suelo no se podia levantar, y son sus armas unos coseletes de tres dedos de algodon, y hasta en los pies, y flechas, y lanzas largas; y en cayendo la gente de pié, los mataba todos. Aquí en este reencuentro me hirieron muchos Españoles y á mí con ellos, que me dieron un flechazo que me pasaron la pierna y entró la flecha por la silla, de la cual herida quedo liciado, que me quedó la una pierna mas corta que la otra, bien cuatro dededos; y en este pueblo me fué forzado estar cinco dias por curarnos, y al cabo de ellos me partí para otro pueblo, llamado Tacuxcalco á donde envié por corredores del campo á Don Pedro y á otros compañeros, los cuales prendieron dos espías, que dijeron como adelante estaba mucha gente de guerra del dicho pueblo y de otros sus comarcanos esperándonos; y para mas certificar, llegaron hasta ver la dicha gente y vieron mucha multitud de ella: á la sazon llegó Gonzalo de Alvarado con cuarenta de caballo, que llevaba la delantera porque yo venía coino he dicho, malo de la herida, y hizo cuerpo hasta tanto que llegamos todos; y llegamos y recojida toda la gente, cabelgué en un caballo, como pude, por mejor poder dar órden como se acometiesen; y ví que habia un cuerpo de gente de guerra, toda hecha una batalla de enemigos y envié á Gomez de Alvarado, que acometiese por la 
mano izquierda con veinte de caballo, y Gonzalo de Alvarado por la mano derecha con treinta de caballo, y Jorge de Alvarado rompiese con todos los demas por la gente; que verla de lejos era para espantar, porque tenian todos los mas lanzas de treinta palmos, todas enarboladas, y yo me puse en un cerro por ver bien como se hacía, y ví que llegaron todos los Españoles hasta un juego de Herron de los indios; y que ni los indios huian ni los españoles acometian, que yo estuve espantado de los indios que así osaron esperar. Los españoles no los habían acometido; porque pensaban que un prado que se hacía en medio de los unos y de los otros era ciénega; y despues que vieron estaba teso y bueno rompieron por los indios, y desvaratándolos, y fueron siguiendo el alcance por el pueblo mas de una legua, y aquí se hizo muy gran matanza y castigo; y como los pueblos de adelante vieron, que en campo los desvaratábamos, determinaron de alzarse y dejarnos los pueblos; y en este pueblo holgué dos dias; y al cabo de ellos me partí para un pueblo, que se dice Miagonaclan y tambien se fueron al monte como los otros. Y de aquí me partí para otro pueblo, que se dice Atehuan y de allí me enviaron los Señores de Cuxcaclan sus mensajeros para que diesen la obediencia á Sus Magestades; y á decir que ellos querian ser sus Vasallos y ser buenos: y así la dieron á mí en su nombre y yo los recibí pensando que no me mentirian como los otros: y llegando que llegué á esta Ciudad de Cuxcaclan, hallé muchos indios que me recibieron y todo el pueblo alzado; y mientras nos aposentamos no quedó hombre de ellos en el pueblo, que todos se fueron á las sierras. Y como ví esto yo envié mis mensajeros á los Señores de allí á decirles, 
que no fuesen malos y que mirasen que habian dado la obediencia á su Magestad, y á mí en su nombre, asegurándoles que viniesen, que yo no les iba á hacer guerra ni á tomarles lo suyo, sinó á traerlos al servicio de Dios Nuestro Señor y de Su Magestad (enviaronme á decir que no conocían á nadie) que no querían venir, que si algo les quería, que allí estaban esperando con sus armas. Y desque ví su mal propósito, les envié un mandamiento y requerimiento de parte del Emperador Nuestro Señor, en que les requería y mandaba que no quebrantasen las paces, ni se revelasen, pues ya se habian dado por sus vasallos: donde no, que procedería contra ellos, como traidores alzados y revelados contra el servicio de su Magestad, y que les haría la guerra y todos los que en ella fuesen tomados á vida serían esclavos, y los herrarian; y que si fuesen leales de mí serian favorecidos y amparados como Vasallos de $\mathrm{Su}$ Magestad. $Y$ á esto ni volvieron los mensajeros ni respuesta de ellos; y como ví su dañada intencion y porque aquella tierra no quedase sin castigo envié gente á buscarlos á los montes y sierras, los cuales hallaron de guerra y pelearon con ellos, y hirieron españoles é indios, mis amigos, y despues de todo esto fué preso un principal de esta Ciudad, y para mas justificacion se lo torné á enviar con otro mi mandamiento y respondieron lo mismo, que antes, é luego como ví esto yo hice proceso contra ellos y contra los otros, que me habían dado la guerra y los llamé por pregones y tampoco quisieron venir, y como ví su rebeldía y el proceso cerrado, lo sentencié y dí por traidores y á pena de muerte á los Señores de estas provincias y á todos los demas que se hubiesen tomado durante la guerra, y se tomasen despues, hasta en tanto, que die- 
sen la obediencia á Su Magestad, fuesen esclavos y se herrasen, y de ellos y de su valor, se pagasen once caballos, que en la conquista de ellos fueron muertos, y los que de aquí adelante matasen y mas las otras cosas de armas y otras cosas necesarias á la dicha conquista. Sobre estos indios de esta dicha Ciudad de Cuxcaclan, que estuve diez y siete dias, que nunca por entradas que mandé hacer, ni mensajeros que les hice, como he dicho, les pude atraer, por la mucha espesura de montes y grandes sierras y quebradas y otras muchas fuerzas que tenian.

Aquí supe de muy grandes tierras, la tierra adentro, Ciudades de Cal y canto y supe de los naturales como esta tierra no tiene cabo, y para conquistarse, segun es grande y de muy grandísimas poblaciones, es menester mucho espacio de tiempo, y por el recio invierno, que entra no pasé mas adelante á conquistar, antes acordé me volver á esta Ciudad de Guatemala, y de pacificar de vuelta la tierra que atras dejaba, y por cuanto hice y en ello trabajé nunca los pude atraer al servicio de su Magestad, porque toda esta costa del Sur por donde fuí es muy montosa y las sierras cerca donde tienen el acojida: así que yo soy venido á esta Ciudad por las muchas aguas á donde para mejor conquistar y pacificar esta tierra tan grande y tan recia de gente, hice y edifiqué en nombre de su Magestad una Ciudad de españoles, que se dice la Ciudad de Señor Santiago; porque desde aquí está en el riñon de toda la tierra y hay mas y mejor aparejo para la dicha conquista $\mathrm{y}$ pacificacion $\mathrm{y}$ para poblar lo de adelante, y elegí dos Alcaldes Ordinarios y cuatro regidores, segun Vuestra Merced allá verá por la eleccion.

Pasados estos dos meses de invierno, que que- 
dan que son los mas recios de todo, saldré de esta Ciudad en demanda de la provincia de Tepalan, que está quince jornadas de aquí, la tierra adentro, que segun soy informado, es la Ciudad tan grande como esa de Méjico y de grandes edificios $y$ de cal y canto y azoteas; y sin esta hay otras muchas, y cuatro ó cinco de ellas han venido aquí á mí á dar la obediencia á su Magestad, y dicen que la una de ellas tiene treinta mil vecinos; no me maravillo, porque segun son grandes los pueblos de esta costa, que la tierra adentro haya lo que dicen; este verano que viene, placiendo á Nuestro Señor, pienso pasar doscientas leguas adelante, donde pienso, su Magestad será muy servido y su estado aumentado, y Vuestra Merced tendrá noticias de otras cosas nuevas. Desde esa Ciudad de Méjico, hasta lo que yo he andado y conquistado hay cuatrocientas leguas: y crea Vuestra Merced, que es mas poblada esta tierra y demas gente, que toda la que Vuestra Merced hasta ahora ha gobernado.

En esta tierra hemos hallado una sierra, do está un volcan, que es la mas espantable cosa que se ha visto, que hecha por la boca piedras, tan grandes como una casa, ardiendo en vivas llamas, y cuando caen se hacen pedazos y cubren toda la sierra de fuego.

Adelante de esta, sesenta leguas, vimos otro volcan, que echa humo y muy espantable, que sube al cielo, y de anchor de compas de media legua, el bulto del humo. Todos los rios, que de allí descienden, no hay quien beba el agua, porque sabe á azufre, y especialmente vine de allí un rio caudal, muy hermoso, tan ardiendo, que no le podian pasar cierta gente de mi compañía que iba á hacer una entrada, y andando á buscar bado, halla- 
ron otro rio frio, que entraba en este, y allí donde se juntaba hallaron bado templado, que lo pudieron pasar. De las cosas de estas partes no hay mas, que hacer saber á Vuestra Merced, sino que me dicen los Indios, que de esta mar del Sur á la del Norte, hay un invierno y un verano, de andadura.

Vuestra Merced, me hizo merced de la Tenencia de esa Ciudad, y yo la ayudé á ganar, y la defendí cuando estaba dentro, con el peligro y trabajo que Vuestra Merced sabe, y si yo hubiera ido en España, por lo que Yo á su Magestad he servido, me la confirmara y me hiciera mas mercedes: hanme dicho, que su Magestad, ha proveido, no me maravillo, pues que de mí no tiene noticia, y de esto no tiene nadie la culpa sino Vuestra Merced, por no haber hecho relacion á su Magestad de lo que yo le he servido, pues me envió acá: Suplico á Vuestra Merced le haga relacion de quien yo soy, y de lo que á Su Magestad he servido en estas partes y donde ando, y lo que nuevamente le he conquistado y la voluntad que tengo de le servir, y en lo de adelante, y como en su servicio me han liciado de una pierna y cuan poco sueldo hasta ahora he ganado yo y estos hidalgos que en mi compañía andan, y el poco provecho, que hasta ahora se nos ha seguido. Nuestro Señor prosperamente crezca la vida, y muy magnífico estado de Vuestra Merced para largos tiempos. De esta Ciudad de Santiago á veintiocho de Julio de mil y quinientos y veinticuatro años.

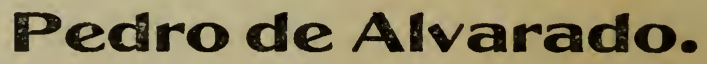




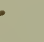




